\title{
The Partnership to Improve Diabetes Education Trial: a Cluster Randomized Trial Addressing Health Communication in Diabetes Care
}

\author{
Richard O. White, MD, MSc ${ }^{7}$ (D), Rosette James Chakkalakal, MD, MHS \\ Kenneth A. Wallston, PhD ${ }^{3}$, Kathleen Wolff, APRN, BC-FNP, BC-ADM ${ }^{4}$, \\ Becky Gregory, MS, RD, LDN, CDE , Dianne Davis, RD, LDN, CDE 5 , David Schlundt, PhD', \\ Karen M. Trochez, MLAS $S^{3}$, Shari Barto, MBA, CCRP 3 , Laura A. Harris, RD, MVTE, CDE', \\ Aihua Bian, MPH', Jonathan S. Schildcrout, $P h D^{8}$, Sunil Kripalani, MD, MSC, SFHM ${ }^{2,3}$, and \\ Russell L. Rothman, MD, MPP 2,3
}

\begin{abstract}
'Division of Community Internal Medicine, Mayo Clinic, Jacksonville, FL, USA; ${ }^{2}$ Department of General Internal Medicine and Public Health, Vanderbilt University Medical Center, Nashville, TN, USA; ${ }^{3}$ Center for Health Services Research, Vanderbilt University Medical Center, Nashville, TN, USA; ${ }^{4}$ School of Nursing, Vanderbilt University Medical Center, Nashville, TN, USA; ${ }^{5}$ Vanderbilt Diabetes Research and Training Center, Vanderbilt University Medical Center, Nashville, TN, USA; ${ }^{6}$ Department of Psychology, Vanderbilt University, Nashville, TN, USA; ${ }^{7}$ Mid-Cumberland Regional Office, Tennessee Department of Health , Nashville, TN, USA; ${ }^{8}$ Department of Biostatistics, Vanderbilt University, Nashville, TN, USA.
\end{abstract}

BACKGROUND: Effective type 2 diabetes care remains a challenge for patients including those receiving primary care in safety net settings.

OBJECTIVE: The Partnership to Improve Diabetes Education (PRIDE) trial team and leaders from a regional department of health evaluated approaches to improve care for vulnerable patients.

DESIGN: Cluster randomized controlled trial.

PATIENTS: Adults with uncontrolled type 2 diabetes seeking care across 10 unblinded, randomly assigned safety net clinics in Middle TN.

INTERVENTIONS: A literacy-sensitive, provider-focused, health communication intervention (PRIDE; 5 clinics) vs. standard diabetes education (5 clinics).

MAIN MEASURES: Participant-level primary outcome was glycemic control [Alc] at 12 months. Secondary outcomes included select health behaviors and psychosocial aspects of care at 12 and 24 months. Adjusted mixed effects regression models were used to examine the comparative effectiveness of each approach to care.

KEY RESULTS: Of 410 patients enrolled, 364 (89\%) were included in analyses. Median age was 51 years; Black and Hispanic patients represented $18 \%$ and 25\%; 96\% were uninsured, and $82 \%$ had low annual income level $(<\$ 20,000)$; adequate health literacy was seen in $83 \%$, but numeracy deficits were common. At 12 months, significant within-group treatment effects occurred from baseline for both PRIDE and control sites: adjusted Alc $(-0.76$ [95\% CI, -1.08 to -0.44$] ; P<.001$ vs $-0.54[95 \%$ $\mathrm{CI},-0.86$ to -0.21$] ; P=.001)$, odds of poor eating $(0.53$ [95\% CI, 0.33-0.83]; $P=.01$ vs 0.42 [95\% CI, 0.26-0.68]; $P<.001$ ), treatment satisfaction (3.93 [95\% CI, 2.48-

Electronic supplementary material The online version of this article (https://doi.org/10.1007/s11606-019-05617-z) contains supplementary material, which is available to authorized users.

Received June 27, 2019

Accepted December 12, 2019

Published online January 9, 2020
6.21]; $P<.001$ vs 3.04 [95\% CI, 1.93-4.77]; $P<.001$ ), and self-efficacy (2.97 [95\% CI, 1.89-4.67]; $P<.001$ vs 1.81 [95\% CI, 1.1-2.84]; $P=.01$ ). No significant difference was observed between study arms in adjusted analyses. CONCLUSIONS: Both interventions improved the participant's Alc and behavioral outcomes. PRIDE was not more effective than standard education. Further research may elucidate the added value of a focused health communication program in this setting.

KEY WORDS: diabetes care; disparities; health communication; vulnerable populations; public health.

Abbreviations

ARMS Adherence to Refills and Medication Scale

Alc Hemoglobin Alc

BMI Body mass index

DNT Diabetes Numeracy Test

DTSQ Diabetes Treatment Satisfaction Questionnaire

NDEP National Diabetes Education Program

$\mathrm{PCMH} \quad$ Patient-centered medical home

PDQ Personal Diabetes Questionnaire

PDSMS Perceived Diabetes Self-Management Scale

PRIDE Partnership to Improve Diabetes Education

SDSCA Summary of Diabetes Self-Care Activities

s-TOFHLA Short Test of Functional Health Literacy in Adults

$\mathrm{TDOH} \quad$ Tennessee Department of Health

T2D Type 2 diabetes mellitus

J Gen Intern Med 35(4):1052-9

DOI: $10.1007 / \mathrm{s} 11606-019-05617-\mathrm{z}$

(c) Society of General Internal Medicine 2020

\section{INTRODUCTION}

The US burden of type 2 diabetes (T2D) is significant, ${ }^{1}$ and despite the benefits of improving glycemic control on clinical outcomes, only 50 to $59 \%$ of patients meet treatment 
recommendations. ${ }^{2}$ Several medically vulnerable populations, including racial/ethnic minorities and low income patients, ${ }^{3,4}$ experience disproportionate rates of diabetes-related complications due to a number of patient, provider, and health system factors. ${ }^{5,6}$ Patient-provider interactions around diabetes are especially challenging for populations with limited health literacy and numeracy. ${ }^{7,8}$ Our work has shown that lower health literacy or numeracy is independently associated with lower quality of diabetes knowledge, self-management, selfefficacy, and glycemic control (A1c). ${ }^{9-12}$ Fortunately, we have shown that efforts to address literacy and numeracy can improve diabetes care ${ }^{13-16}$ in academic settings.

In 2010, we partnered with the Mid-Cumberland Region of the Tennessee Department of Health (TDOH) to develop the Partnership to Improve Diabetes Education (PRIDE) trial. ${ }^{17}$ Our purpose was to translate our prior health communication research to the community level and inform models of care targeting glycemic control in vulnerable populations. TDOH clinics provide primary care for predominantly uninsured patients with multiple socioeconomic challenges. TDOH patients with diabetes had poor diabetes quality indicators despite previous state-level care collaboratives. ${ }^{18}$ The PRIDE study compared two distinct care approaches: one based on content from the National Diabetes Education Program $(\mathrm{NDEP})^{19}$ and one centered on addressing issues of health communication (PRIDE) to evaluate the potential benefits of focusing on health communication issues in this vulnerable population.

\section{RESEARCH DESIGN AND METHODS}

\section{Setting and Population}

The TDOH operates 95 sites ( 54 rural) which provide primary care for an uninsured, vulnerable population. The MidCumberland Region has 16 clinics across 12 counties. TDOH clinics reported average A1c near $10 \%(86 \mathrm{mmol} / \mathrm{mol})$ for the 2 years preceding PRIDE, according to internal quality data. Clinics were considered for study participation if they could support at least 40 eligible patients, engage 2-4 health care providers, and agree to randomization and the 2-year study duration. At each TDOH clinic, patients have access to primary care providers, registered nurses, a registered dietician, health educator, in-house pharmacy, certified diabetes educator, and Spanish interpreters.

\section{Study Design}

To test the effectiveness of the PRIDE intervention relative to NDEP on participant level glycemic control, we performed a cluster randomized controlled design. Using a multivariable score-based, pair-wise matching randomization, we sought to optimize balance across sites by clinic size, prevalence of Spanish-speaking patients, average A1c levels, and other patient characteristics (age, sex, race, insurance status, insulin status, weight). Five clinics were randomized to PRIDE and 5 to NDEP.

\section{Recruitment}

Bilingual research assistants (RA) and clinic staff identified patients at participating sites. Patient-level inclusion criteria were adults (age 18-85 years) with a clinical diagnosis of T2D, English or Spanish speaking, a most recent A1c greater than $7.5 \%(58 \mathrm{mmol} / \mathrm{mol})$, and agreement with the 2-year study. Patients were excluded for poor visual acuity $(<20 /$ 50 ), personal history of dementia or psychosis, or life expectancy less than 2 years. All consenting TDOH providers were also enrolled.

Appropriate approvals were secured from TDOH and Vanderbilt University IRBs. Verbal and written informed consent was obtained from patient participants in their preferred language before enrollment. After randomization, the participants received a total of $\$ 90$ after data completion. Providers received continuing education credits for their engagement.

\section{PRIDE Intervention Group}

PRIDE is a multicomponent educational curriculum targeting multidisciplinary providers of diabetes care (https://www. vumc.org/cehc/pride-study). We previously have published on the development and evaluation of the PRIDE toolkit. ${ }^{20}$ It addresses a spectrum of diabetes self-management content incorporated from 2 previously validated sources, the Diabetes Literacy and Numeracy Educational Toolkit ${ }^{16}$ and The American College of Physicians Foundation Living With Diabetes Guide. ${ }^{21}$ The PRIDE toolkit was developed for low-literacy populations by incorporating plain language written at the 46th-grade reading level along with several strategies known to enhance understanding. These include optimizing the use of white space, conveying information with pictographs and simplified tables, eliminating medical jargon, and minimizing topics covered. $^{22}$

Each PRIDE toolkit section ends with a shared decisionmaking task where important points from the module are summarized and optional action points are presented allowing for use of specific communication strategies such as teach back or teaching to goal. ${ }^{23,24}$ Another important aspect is its parallel Spanish version that followed an iterative process of cultural adaptation involving translation and back-translation, input from bilingual content experts, cognitive interviews with the target audience, and pilot testing. Finally, PRIDE participants received branded dining placements that promote a modified plate method for achieving dietary goals. ${ }^{25}$

In total, 100 providers $(20 \mathrm{MD} / \mathrm{NP} ; 8 \mathrm{RD}, 9$ interpreters, 63 nurses) from the 5 PRIDE sites participated in enhanced trainings which occurred annually at Vanderbilt University Center for Experiential Learning and Assessment (CELA). Sessions included updates in diabetes, instruction on techniques to improve health communication, use of the PRIDE toolkit, and sessions with simulated patients. Booster trainings 
occurred at the clinic sites between annual trainings and included didactic sessions on health communication with trigger videos to promote intervention fidelity. We provided staff access to trainings and materials (https://www.vumc.org/ cehc/pride-study).

\section{NDEP Sites}

Eighty-six providers (18 MD/NP, $8 \mathrm{RD}, 14$ interpreters, 46 nurses) from the 5 comparator sites received annual NDEP education at Vanderbilt with access to online content and local booster trainings at intervals similar to the PRIDE group. Small group discussions with case reviews were led by Vanderbilt University Center for Diabetes Translational Research faculty. $\mathrm{TDOH}$ staff at standard sites did not receive additional instruction on improving communication skills or the PRIDE toolkit.

\section{Main Measures}

RAs administered all measures in English or Spanish. At baseline, patients provided demographic characteristics and answered validated questionnaires assessing health literacy (Short Test of Functional Health Literacy in Adults [s-TOFHLA] ${ }^{26}$ numeracy (Diabetes Numeracy Test $[\mathrm{DNT}]),{ }^{27,28}$ and self-management behaviors. Scores on the s-TOFHLA identified individuals with adequate $(\geq 23)$, marginal (16-22), or inadequate $(<16)$ health literacy. The DNT is a 5-question measure of diabetes-specific numeracy. Self-management behaviors were assessed with the Summary of Diabetes Self-Care Activities (SDSCA) ${ }^{29}$ and the Personal Diabetes Questionnaire (PDQ). ${ }^{30}$ Medication nonadherence was measured with the Adherence to Refills and Medication Scale (ARMS) ${ }^{31}$; treatment satisfaction and diabetes self-efficacy were measured with the Diabetes Treatment Satisfaction Questionnaire (DTSQ) ${ }^{32}$ and the Perceived Diabetes SelfManagement Scale (PDSMS). ${ }^{33}$ Higher scores indicate greater presence of the measured construct. Clinical measures, including $\mathrm{A} 1 \mathrm{c}$, blood pressure, and BMI, were repeated at 3-month intervals; self-management behaviors were reassessed at $6,12,18$, and 24 months.

\section{Statistical Analysis}

The PRIDE study followed participants for up to 2 years; however, our prespecified primary analysis was improvement in A1c at 12-months for the PRIDE group compared with the NDEP group. Sample size calculations were derived from a simulation study of the primary outcome. We anticipated a $0.8 \%$ improvement in Alc from baseline to 12 months, conservatively estimating a standard deviation of 2.0 derived from changes in A1c from previous preliminary work. ${ }^{13}$ Clustering effects by site and provider were considered through inclusion of an intraclass correlation coefficient (ICC) set to 0.04 , which represented the median ICC of 13 cluster RCT's in primary care reported from 1997 through $2000 .^{34}$ For 410 recruited patients, with an anticipated $30 \%$ loss to follow-up, the power was estimated to be $85.1 \%$ at a 2 -sided significance at $P<.05$.
We describe baseline patient characteristics with median and interdecile range (10th percentile-90th percentile) for continuous variables. We used Wilcoxon rank sum tests for unadjusted comparisons between arms. We summarized categorical variables with frequencies and proportions and used $\chi^{2}$ tests for unadjusted comparisons. To address patient-level imbalances between arms, we performed regression analysis with adjustment for the prespecified covariates of age, sex, race/ethnicity, s-TOFHLA score, insurance status, annual income, numeracy score, years of education, and baseline BMI. To estimate treatment effects at 12 and 24 months, we used linear mixed models for the continuous outcomes of A1c, BMI, LDL, and SDSCA and used proportional odds mixed models for the ordinal outcomes of PDQ, ARMS, DTSQ, and PDSMS.

For each analysis, we included a treatment arm indicator as a fixed effect, sites as random effects, and, in addition to other covariates, the baseline value of the outcome. To examine changes within each treatment arm from baseline, we used nested (participants within sites) random effects models. Each model admitted 2 records per patient (baseline and 12 months or baseline and 24 months). A treatment arm by time interaction was included in each model to capture the within-arm change in outcome values from baseline. To be included in the analyses, trial participants had to have follow-up outcome data at 1 or more of the scheduled clinic visits after enrollment. When outcome data at 12 or 24 months were missing, we used covariate data, as well as outcome data from other time points, to multiply impute the outcome (100 times) using predictive mean matching. Estimates from the imputation-specific analyses were combined with Rubin's Rule. ${ }^{35,36}$ All analyses were conducted with $\mathrm{R}$ software version 3.3.0 (R Project, http:// www.r-project.org).

\section{KEY RESULTS}

From July 5, 2011, through April 29, 2013, 573 patients were recruited, and 163 patients declined or were ineligible. In total, 410 patients consented and enrolled. Forty-six patients did not have adequate follow-up data; thus, analyses consist of 364 patients (89\%). Following clinic level randomization, 212 participants received care at PRIDE sites and 198 participants at NDEP sites (Fig. 1). At 12 months, participant retention rates were $60 \%$ (PRIDE) and 63\% (NDEP). The median age was $51(36-60)$ and $61 \%$ were female; White and Black participants comprised $63 \%$ and $18 \%$ of the combined sample (see Table 1) while $25 \%$ self-identified as Hispanic. Most participants had low annual income $(82 \%<\$ 20,000)$, and the median diabetes duration was $8.0(1.0-20.0)$ years. Median BMI was $34(27-47) \mathrm{kg} / \mathrm{m}^{2}$ and A1c was $9.2 \%(7.5-$ $12.3 \%)(77[58-111] \mathrm{mmol} / \mathrm{mol})$. Most participants had adequate health literacy, but deficits of numeracy were common, with median DNT scores of 40\% (0-100\%). Following randomization, demographic characteristics and diabetes-related 


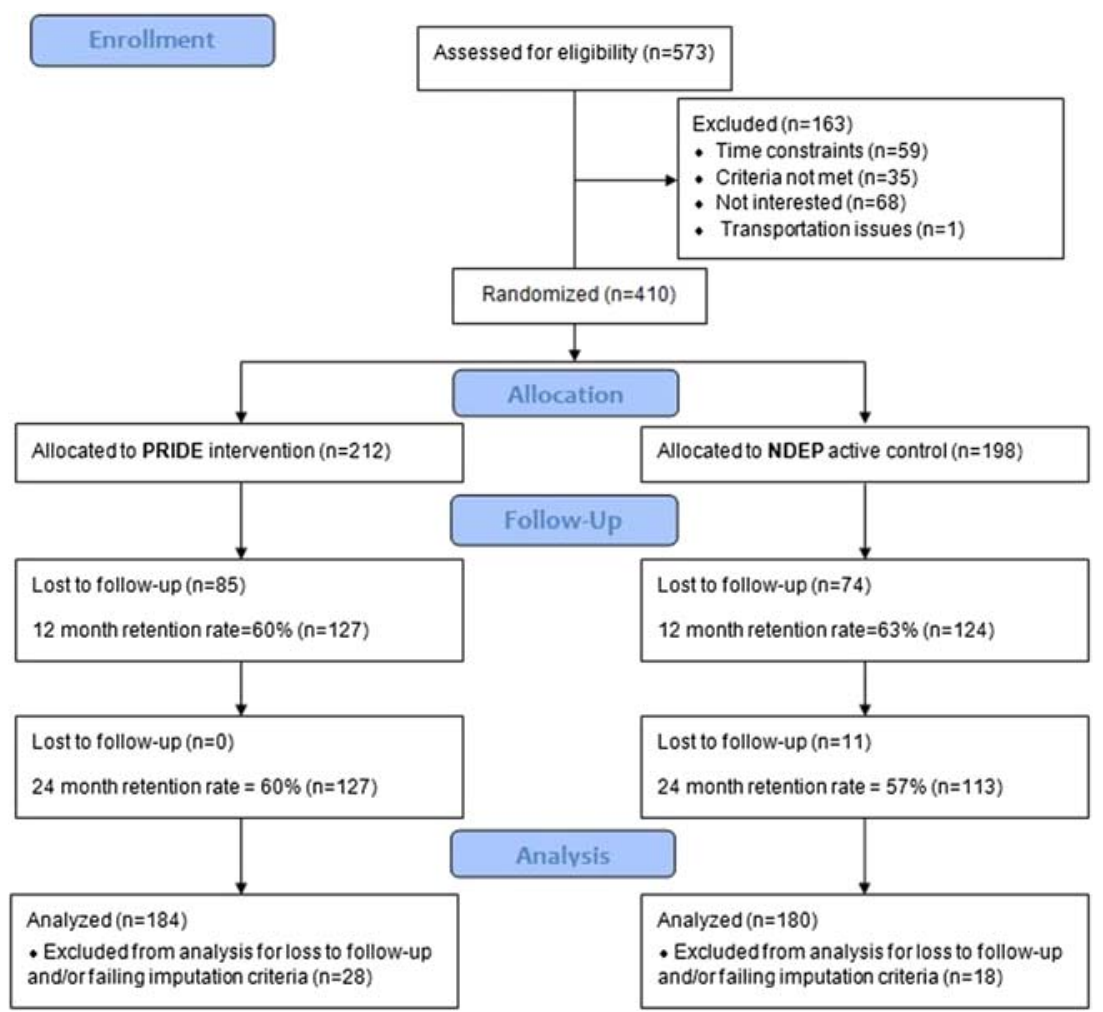

Fig. 1 PRIDE study consolidated standards of reporting trials flow diagram. NDEP, National Diabetes Education Program; PRIDE, Partnership to Improve Diabetes Education.

Table 1 Baseline Characteristics of Patients Included Only in the Analysis by Study Arm

\begin{tabular}{|c|c|c|c|c|}
\hline Characteristic $^{\mathrm{a}}$ & $\begin{array}{l}\text { Total }(n= \\
\text { 364) }\end{array}$ & $\begin{array}{l}\text { NDEP }(n= \\
180)\end{array}$ & $\begin{array}{l}\text { PRIDE }(n= \\
\text { 184) }\end{array}$ & $P$ value ${ }^{\mathrm{b}}$ \\
\hline Age (years) & $51(36-60)$ & $50(37-60)$ & $51(36-60)$ & .40 \\
\hline Female sex & $221(61)$ & $108(60)$ & $113(61)$ & .78 \\
\hline \multicolumn{5}{|l|}{ Race } \\
\hline White & $230(63)$ & $107(59)$ & $123(67)$ & .28 \\
\hline Black & $64(18)$ & $33(18)$ & $31(17)$ & \\
\hline Other & 70 (19) & $40(22)$ & $30(16)$ & \\
\hline Hispanic ethnicity & $90(25)$ & $44(24)$ & $46(25)$ & .90 \\
\hline Annual income $<\$ 20,000$ & $296(82)$ & $147(82)$ & $149(82)$ & .95 \\
\hline Time since T2D diagnosis (years) & $8.0(1.0-20.0)$ & $8.0(1.0-18.4)$ & $7.0(1.1-20.0)$ & .91 \\
\hline Education (years) & $12(6-14)$ & $12(6-14)$ & $12(6-15)$ & .60 \\
\hline s-TOFHLA score & $34(12-36)$ & $34(14-36)$ & $34(10-36)$ & .61 \\
\hline DNT score (range $0.0-1.0$ ) & $0.4(0.0-1.0)$ & $0.4(0.0-1.0)$ & $0.4(0.0-1.0)$ & .27 \\
\hline Uninsured participants & $345(96)$ & $167(93)$ & $178(98)$ & .04 \\
\hline $\mathrm{A} 1 \mathrm{c}(\%)^{\mathrm{c}} \mathrm{P}(\mathrm{P})$ & $9.2(7.5-12.3)$ & $9.1(7.5-12.0)$ & $9.2(7.5-12.8)$ & .47 \\
\hline $\mathrm{A} 1 \mathrm{c}(\mathrm{mmol} / \mathrm{mol})^{\mathrm{c}}$ & $77(58-111)$ & $76(58-108)$ & $77(58-116)$ & 47 \\
\hline BMI $\left(\mathrm{kg} / \mathrm{m}^{2}\right)$ & $34(27-47)$ & $35(28-49)$ & $34(26-46)$ & .10 \\
\hline LDL-C $(\mathrm{g} / \mathrm{dL})^{\mathrm{c}}$ & $100(55-148)$ & $98(62-150)$ & $102(53-142)$ & .72 \\
\hline \multicolumn{5}{|l|}{ Diabetes-related behaviors } \\
\hline Summary of Diabetes Self-care Activities (range, $0-91$ ) & $58(37-77)$ & $59(39-77)$ & $56(33-76)$ & .06 \\
\hline Personal Diabetes Questionnaire use (range, $3-18$ ) use of data to modify diet ${ }^{\mathrm{c}}$ & $8(3-15)$ & $9(3-16)$ & $7(3-14)$ & .02 \\
\hline Personal Diabetes Questionnaire (range, $3-18$ ) poor eating behavior ${ }^{\mathrm{c}}$ & $10(6-15)$ & $10(6-14)$ & $10(5-15)$ & .67 \\
\hline Adherence to Refills and Medication Scale (range, $12-48)^{\mathrm{c}}$ & $17(12-23)$ & $17(12-23)$ & $16(12-23)$ & .75 \\
\hline Diabetes Treatment Satisfaction Questionnaire (range, $0-36)^{c}$ & $30(20-36)$ & $30(21-36)$ & $29(19-35)$ & .07 \\
\hline Perceived Diabetes Self-Management Scale (range, 8-40) & $16(10-24)$ & $16(10-25)$ & $16(9-23)$ & .16 \\
\hline
\end{tabular}

BMI, body mass index; DNT, diabetes numeracy test; Alc, hemoglobin Alc; LDL-C, low-density lipoprotein cholesterol; NDEP, National Diabetes Education Program; PRIDE, Partnership to Improve Diabetes Education; s-TOFHLA, Short Test of Functional Health Literacy in Adults

${ }^{a}$ Data are expressed as no. (\%) or median (10th percentile-90th percentile)

${ }^{b}$ Calculated with Pearson $\chi^{2}$ test for categorical variables and Wilcoxon rank sum test for continuous variables

${ }^{c}$ Descriptive statistics at baseline for each outcome measure 
behaviors were evenly distributed across sites except for insurance status $(P=.04)$ and use of data to modify diet $(P=.02)$. No differences in baseline characteristics were observed between the participants included vs those excluded from primary analyses (Supplementary Tables S1 and S2).]->

Figure 2 shows unadjusted trends in Alc levels. In both arms, we observed significant decreases from baseline. However, the covariate-adjusted difference (PRIDE minus NDEP) in the average $\mathrm{A} 1 \mathrm{c}$ at 12 months was nonsignificant (mean [95\% CI] difference, $-0.11 \%[-0.65$ to $0.44 \%] ; P=.70$ ). Within-group decreases in A1c from baseline to 12 months were substantial for both arms, with an adjusted change of $0.76 \%(95 \% \mathrm{CI},-1.08$ to $-0.44 \%)(P<.001)$ in the PRIDE arm and $-0.54 \%(95 \% \mathrm{CI},-0.86$ to $-0.21 \%)(P=.001)$ in the NDEP arm. In the primary analysis model, we observed that Hispanic ethnicity and higher DNT scores were associated with significantly lower 12-month A1c scores. Hispanic ethnicity was associated with a $-1.09 \%(95 \% \mathrm{CI},-1.87$ to $0.31 \%)(P=.01)$ and a 1 -unit increase in the DNT was associated with a $-0.74 \%(95 \% \mathrm{CI},-1.46$ to $-0.02 \%)(P=.04)$ change in 12-month A1c.] $\rightarrow$

In analyses of secondary 12-month outcomes, participants exposed to PRIDE had significantly higher LDL levels (mean [95\% CI] difference, 14.97 [5.95-24.00] g/dL; $P=.001)$ and lower odds of data use to modify diets (odds ratio [95\% CI], $0.49[0.30-0.81] ; P=.01)$ compared with NDEP participants (Table 2). We did not observe any other significant differential effects of PRIDE relative to NDEP among the other secondary outcome variables. In contrast, within treatment arms, we again observed improvements from baseline to 12 months in patient reports of self-care activities, poor eating behaviors, medication nonadherence (NDEP only), diabetes treatment satisfaction, and self-efficacy. These observed within-group changes in behavioral outcomes were sustained for each treatment arm at 24 months. However, only the PRIDE group maintained significant within-group decreases in A1c (mean $[95 \% \mathrm{CI}]$ difference, $-0.76[-1.13$ to -0.40$] ; P<.001)$ vs (NDEP) (mean [95\% CI] difference, -0.36 [ -0.75 to 0.03$]$; $P=.07$ ) at 24 months (Supplementary Table 3).

\section{CONCLUSIONS}

The PRIDE trial failed to demonstrate superiority at lowering 12-month A1c relative to a rigorously delivered, NDEP-based, standard educational approach. Both programs, however, had significant impact on glycemic control and several behavioral outcomes. PRIDE was evidence-based, had favorable efficacy data in the academic setting, and was developed with input from content experts and multiple rounds of cultural adaptability testing. We created a strong collaboration with our TDOH system who served as effective research partners. Both study conditions positively impacted patient's self-care behaviors, eating habits, and perceived level of confidence in their self-care. Participants reported significantly greater satisfaction with their care at 12 months. The PRIDE intervention appeared to have modest evidence for greater sustainability of within-group impact on glycemic control than NDEP at 24 months.

Nonetheless, the null effect of PRIDE vs. NDEP requires explanation as previous studies have highlighted the importance of addressing communication issues with vulnerable populations. One explanation is that NDEP represented a standard of care that was better than the usual care for this population. This is supported by prior challenges in achieving glycemic control for the TDOH diabetes population. Safetynet clinics often differ in their available infrastructure and capacity for providing standard diabetes care, ${ }^{37}$ and usual care, particularly in safety-net settings, is often influenced by barriers to the delivery of evidenced-based care. ${ }^{38}$ These barriers

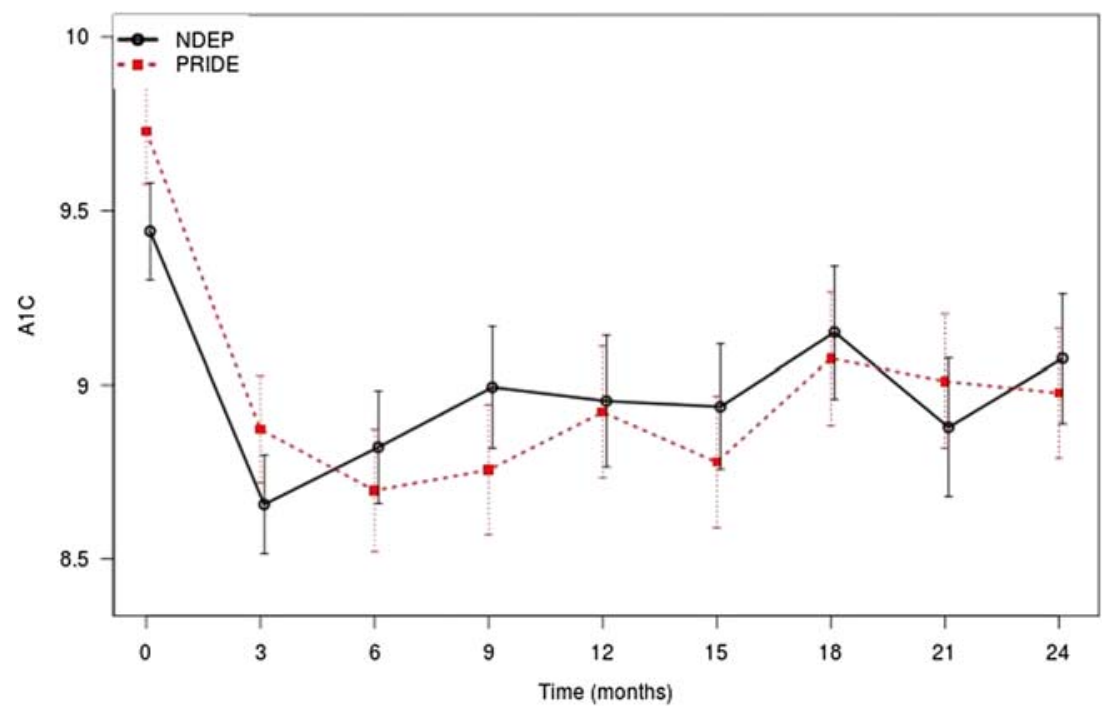

Fig. 2 Differential impact of PRIDE vs NDEP conditions on change in A1c from baseline to 24 months. Error bars indicate 95\% CI. A1c, hemoglobin A1c; NDEP, National Diabetes Education Program; PRIDE, Partnership to Improve Diabetes Education. 
Table 2 Change in Clinical and Behavioral Outcomes at 12 Months by Study Arm

\begin{tabular}{|c|c|c|c|c|c|c|}
\hline Outcome variable & Baseline $^{a}$ & At 12 months $^{\mathrm{a}}$ & $\begin{array}{l}\text { Between-group treatment } \\
\text { effect, mean }(95 \% \mathrm{CI})\end{array}$ & $P$ value $^{\mathrm{b}}$ & $\begin{array}{l}\text { Within-group treatment } \\
\text { effect }^{\mathrm{c}} \text {, mean }(95 \% \mathrm{CI})\end{array}$ & $P$ value $^{\mathrm{d}}$ \\
\hline \multicolumn{7}{|l|}{ A1c $(\%)$} \\
\hline $\begin{array}{l}\text { NDEP } \\
\text { PRIDE }\end{array}$ & $\begin{array}{l}9.1(7.5 \text { to } 12.0) \\
9.2(7.5 \text { to } 12.8)\end{array}$ & $\begin{array}{l}8.4(6.8 \text { to } 11.5) \\
8.4(6.6 \text { to } 11.5)\end{array}$ & $-0.11(-0.65 \text { to } 0.44)^{\mathrm{d}}$ & .70 & $\begin{array}{l}-0.54(-0.86 \text { to }-0.21)^{\mathrm{e}} \\
-0.76(-1.08 \text { to }-0.44)^{\mathrm{e}}\end{array}$ & $\begin{array}{l}.001 \\
<.001\end{array}$ \\
\hline \multicolumn{7}{|l|}{ BMI $\left(\mathrm{kg} / \mathrm{m}^{2}\right)$} \\
\hline $\begin{array}{l}\text { NDEP } \\
\text { PRIDE }\end{array}$ & $\begin{array}{l}35(28 \text { to } 49) \\
34(26 \text { to } 47)\end{array}$ & $\begin{array}{l}35(28 \text { to } 50) \\
33(26 \text { to } 46)\end{array}$ & $-0.54(-1.37 \text { to } 0.28)^{\mathrm{d}}$ & .20 & $\begin{array}{l}-0.01(-0.57 \text { to } 0.55)^{\mathrm{e}} \\
-0.31(-0.89 \text { to } 0.26)^{\mathrm{e}}\end{array}$ & $\begin{array}{l}.97 \\
.29\end{array}$ \\
\hline $\begin{array}{l}\text { LDL-C (g/dL) } \\
\text { NDEP } \\
\text { PRIDE }\end{array}$ & $\begin{array}{l}96(56 \text { to } 150) \\
103(54 \text { to } 143\end{array}$ & $\begin{array}{l}84(60 \text { to } 125) \\
104(59 \text { to } 143)\end{array}$ & $14.97(5.95 \text { to } 24.00)^{\mathrm{d}}$ & .001 & $\begin{array}{l}-8.17(-15.15 \text { to }-1.20)^{\mathrm{e}} \\
4.56(-2.08 \text { to } 11.21)^{\mathrm{e}}\end{array}$ & $\begin{array}{l}.02 \\
.18\end{array}$ \\
\hline \multicolumn{7}{|c|}{ Summary of Diabetes Self-Care Activities } \\
\hline $\begin{array}{l}\text { NDEP } \\
\text { PRIDE }\end{array}$ & $\begin{array}{l}59(39 \text { to } 77) \\
56(32 \text { to } 77)\end{array}$ & $\begin{array}{l}68(49 \text { to } 83) \\
62(42 \text { to } 80)\end{array}$ & $-0.73(-8.58 \text { to } 7.13)^{\mathrm{e}}$ & .86 & $\begin{array}{l}8.29(5.49 \text { to } 11.08)^{\mathrm{e}} \\
9.88(7.00 \text { to } 12.76)^{\mathrm{e}}\end{array}$ & $\begin{array}{l}<.001 \\
<.001\end{array}$ \\
\hline \multicolumn{7}{|c|}{ PDQ use of data to modify diet } \\
\hline $\begin{array}{l}\text { NDEP } \\
\text { PRIDE }\end{array}$ & $\begin{array}{l}9(3 \text { to } 16) \\
7(3 \text { to } 15)\end{array}$ & $\begin{array}{l}11(3 \text { to } 18) \\
8(3 \text { to } 15)\end{array}$ & $0.49(0.30 \text { to } 0.81)^{\mathrm{f}}$ & .01 & $\begin{array}{l}1.77(1.10 \text { to } 2.85)^{\mathrm{f}} \\
1.14(0.73 \text { to } 1.77)^{\mathrm{f}}\end{array}$ & $\begin{array}{l}.02 \\
.57\end{array}$ \\
\hline \multicolumn{7}{|c|}{ PDQ poor eating behavior } \\
\hline $\begin{array}{l}\text { NDEP } \\
\text { PRIDE }\end{array}$ & $\begin{array}{l}10(6 \text { to } 14) \\
10(5 \text { to } 14)\end{array}$ & $\begin{array}{l}8(5 \text { to } 13) \\
9(4 \text { to } 14)\end{array}$ & $1.25(0.74 \text { to } 2.09)^{\mathrm{f}}$ & .41 & $\begin{array}{l}0.42(0.26 \text { to } 0.68)^{\mathrm{f}} \\
0.53(0.33 \text { to } 0.83)^{\mathrm{f}}\end{array}$ & $\begin{array}{l}<.001 \\
.01\end{array}$ \\
\hline \multicolumn{7}{|c|}{ Adherence to Refills and Medication Scale (range, 12-48) } \\
\hline $\begin{array}{l}\text { NDEP } \\
\text { PRIDE }\end{array}$ & $\begin{array}{l}17(12 \text { to } 23) \\
17(12 \text { to } 23)\end{array}$ & $\begin{array}{l}15(12 \text { to } 21) \\
16(13 \text { to } 20)\end{array}$ & $1.46(0.89 \text { to } 2.39)^{\mathrm{f}}$ & .13 & $\begin{array}{l}0.49(0.31 \text { to } 0.76)^{\mathrm{f}} \\
0.70(0.45 \text { to } 1.09)^{\mathrm{f}}\end{array}$ & $\begin{array}{l}.002 \\
.11\end{array}$ \\
\hline \multicolumn{7}{|c|}{ Diabetes Treatment Satisfaction Questionnaire (range, 0-36) } \\
\hline $\begin{array}{l}\text { NDEP } \\
\text { PRIDE }\end{array}$ & $\begin{array}{l}30(22 \text { to } 36) \\
28(18 \text { to } 34)\end{array}$ & $\begin{array}{l}34(28 \text { to } 36) \\
33(24 \text { to } 36)\end{array}$ & $0.82(0.51 \text { to } 1.32)^{\mathrm{f}}$ & .41 & $\begin{array}{l}3.04(1.93 \text { to } 4.77)^{\mathrm{f}} \\
3.93(2.48 \text { to } 6.21)^{\mathrm{f}}\end{array}$ & $\begin{array}{l}<.001 \\
<.001\end{array}$ \\
\hline $\begin{array}{l}\text { Perceived Diabetes } \\
\text { NDEP } \\
\text { PRIDE }\end{array}$ & $\begin{array}{l}16(10 \text { to } 24) \\
16(10 \text { to } 22)\end{array}$ & $\begin{array}{l}\text { (range, } 8-40) \\
18(11 \text { to } 27) \\
18(13 \text { to } 28)\end{array}$ & $1.25(0.77 \text { to } 2.03)^{\mathrm{f}}$ & .36 & $\begin{array}{l}1.81(1.16 \text { to } 2.84)^{\mathrm{f}} \\
2.97(1.89 \text { to } 4.67)^{\mathrm{f}}\end{array}$ & $\begin{array}{l}.01 \\
<.001\end{array}$ \\
\hline
\end{tabular}

BMI, body mass index; Alc, hemoglobin Alc; LDL-C, low-density lipoprotein cholesterol; NDEP, National Diabetes Education Program; PDQ, Personal Diabetes Questionnaire; PRIDE, Partnership to Improve Diabetes Education

${ }^{a}$ Data in this column are expressed as median (10th percentile to 90th percentile). These are raw data and are not covariate adjusted

${ }^{b}$ Calculated with linear mixed regression analysis to assess the treatment effect for continuous outcomes and proportional odds mixed models for the ordinal outcomes. Predictive mean matching was used to impute missing data

${ }^{c}$ Within-group effects reflect the impact of the respective study condition on the outcome for that group

${ }^{d}$ Calculated with linear mixed regression analysis with nested random effects to assess the treatment arm changes from baseline for continuous outcomes and with proportional odds mixed models with nested random effects for ordinal outcomes. Predictive mean matching was used to impute missing data

${ }^{e}$ Estimate is difference in means

${ }^{f}$ Estimate is odds ratio

may include lack of family and/or social network support, competing and complex social needs (e.g., transportation, food insecurity), and financial challenges. ., $^{3} 9$

Efforts to improve the quality of care in safety-net settings with emphasis on patient-provider interactions may be insufficient to offset other socioeconomic challenges faced by vulnerable, uninsured patients. We hypothesized that a differentiating factor between PRIDE and NDEP was an anticipated variation in the provider's ability to enhance point of care interactions and other patient-centered treatment skills. We acknowledge that this approach unintentionally ignores other influential factors that occur beyond the clinical encounter. Our findings may underscore the important role of support outside the immediate clinical setting for high-risk vulnerable populations, such as the historical yet reemerging role of community health workers.

Additionally, the added benefit of knowledge gained through a rigorously delivered NDEP may have been sufficient to buffer any incremental impact of PRIDE on the primary outcome. In fact, $23 \%$ of NDEP materials currently available in the online toolshed are classified as developed with "principles of plain language and health literacy". ${ }^{20} \mathrm{In}$ essence, our "standard comparator" appears to have functioned as an effective intervention itself.

\section{Limitations}

We faced several challenges during the trial. Despite focus on study design, securing buy-in from state leadership, and careful communication among our research team and participants, we had significant losses to follow-up (e.g., address change, insurance acquisition, time). This fact is not trivial and likely affected our findings. Both treatment arms had average baseline A1c levels that were elevated, and therefore, our findings may reflect regression to the mean, Hawthorne effects, or patient self-selection. The adoption of the SAVE (Systematic Alien Verification for Entitlements) by the Tennessee legislature prohibited care at the TDOH for patients without legal resident status. This affected the access and likely the follow- 
up for some of the patients during our trial. It also required greater effort to engage our Hispanic participants, as $14 \%$ of those retained had to be monitored off-site.

Potential contamination between sites could have biased the study towards the null result. Occasionally, PRIDE staff was transferred to a NDEP clinic and vice versa. Staff from NDEP sites occasionally asked about communication issues during trainings, so it is possible health communication strategies were discussed in the NDEP group; staff could also potentially share PRIDE materials across clinics, although we urged against this. We acknowledge that our findings should not be presumed generalizable to other populations even those with similar sociodemographics. Finally, we do not have objective evidence that quantifies the improvement of the communication skills for providers who received our training. Direct observation of providers during diabetes care encounters could have mitigated this limitation but was not feasible within the scope of our trial.

\section{SUMMARY}

Effective engagement of a highly vulnerable diabetes population continues to be a challenge. We have demonstrated that a community health communication intervention program can be effective at improving glycemic control and behavioral outcomes, yet rigorously delivered standard care may accomplish similar goals. Regardless of the approach, we are satisfied that important steps have been taken in our region, and many of our front-line providers have gained the skills to engage more effectively with vulnerable diabetes patients. Our training and low-literacy diabetes materials are available to staff in our TDOH, and our community-academic partnership has great potential for eliminating disparities. Our findings are a start, and they provide encouragement for continued translational work to improve care delivery. Our hope is that similar efforts to ensure equitable diabetes care for all populations at increased risk remains a prioritized endeavor.

Acknowledgments: The PRIDE team thanks the leadership at the $T D O H$, especially Cathy Taylor DrPH, RN, and all of the patients who gave their time and efforts. We acknowledge the recruitment efforts of Laura Chambers, Alexis and Nicolas Ludi, and Ricardo Trochez.

Corresponding Author: Richard O. White, MD, MSc; Division of Community Internal Medicine Mayo Clinic, Jacksonville, FL, USA (e-mail: white.richard@mayo.edu).

Author Contributions All authors attest to meeting the International Committee of Medical Journal Editors uniform requirements for authorship. DS, KAW, LAH, JSS, SK, and RLR led the development of the PRIDE partnership, study design, and implementation. ROW, $K W, B P G, D D, S B, S K$, and RLR conducted provider trainings and evaluated the low-literacy materials, including the cultural adaptation of Spanish materials led by ROW. ROW, KMT, and SB were responsible for data and program management and recruitment. $A B$ and JSS led data analyses. ROW, RJC, and JSS led data interpretation and manuscript writing. All authors gave final manuscript approval. ROW guarantees the work.

Funding Information This study was funded by 5R18 DKO83264 and ROW supported by K23 5DK092470 from the NIDDK. Additional support was obtained from Vanderbilt University CTSA 5UL1TR000445, Vanderbilt CDTR DK092986, and study data were collected and managed using Research Electronic Data Capture.

\section{Compliance with Ethical Standards:}

Conflict of Interest: Dr. Rothman is a consultant for edLogics and Abbott, unrelated to the current project.

\section{REFERENCES}

1. Centers for Disease Control and Prevention: National Diabetes Statistics Report. Atlanta (GA), Centers for Disease Control and Prevention, US Department of Health and Human Services, 2017, p. 20

2. Selvin E, Parrinello CM, Sacks DB, Coresh J: Trends in prevalence and control of diabetes in the United States, 1988-1994 and 1999-2010. Ann Intern Med 2014;160:517-525

3. Ali MK, McKeever Bullard K, Imperatore G, Barker L, Gregg EW, Centers for Disease C, Prevention: Characteristics associated with poor glycemic control among adults with self-reported diagnosed diabetesNational Health and Nutrition Examination Survey, United States, 20072010. MMWR Suppl 2012;61:32-37

4. Osborn CY, de Groot M, Wagner JA: Racial and ethnic disparities in diabetes complications in the northeastern United States: the role of socioeconomic status. J Natl Med Assoc 2013;105:51-58

5. Beverly EA, Ganda OP, Ritholz MD, Lee Y, Brooks KM, LewisSchroeder NF, Hirose M, Weinger K: Look who's (not) talking: diabetic patients' willingness to discuss self-care with physicians. Diabetes Care 2012;35: 1466-1472

6. Nam S, Chesla C, Stotts NA, Kroon L, Janson SL: Barriers to diabetes management: patient and provider factors. Diabetes Res Clin Pract 2011;93:1-9

7. White RO, Chakkalakal RJ, Presley CA, Bian A, Schildcrout JS, Wallston KA, Barto S, Kripalani S, Rothman R: Perceptions of Provider Communication Among Vulnerable Patients With Diabetes: Influences of Medical Mistrust and Health Literacy. J Health Commun 2016;21:127134

8. White RO, Eden S, Wallston KA, Kripalani S, Barto S, Shintani A, Rothman RL: Health communication, self-care, and treatment satisfaction among low-income diabetes patients in a public health setting. Patient Educ Couns 2015;98:144-149

9. Cavanaugh K, Huizinga MM, Wallston KA, Gebretsadik T, Shintani A, Davis D, Gregory RP, Fuchs L, Malone R, Cherrington A, Pignone M, DeWalt DA, Elasy TA, Rothman RL: Association of numeracy and diabetes control. Ann Intern Med 2008;148:737-746

10. Osborn CY, Cavanaugh K, Wallston KA, Rothman RL: Self-efficacy links health literacy and numeracy to glycemic control. J Health Commun 2010;15 Suppl 2:146-158

11. Rothman RL, Housam R, Weiss H, Davis D, Gregory R, Gebretsadik T, Shintani A, Elasy TA: Patient understanding of food labels: the role of literacy and numeracy. Am J Prev Med 2006;31:391-398

12. Rothman RL, Malone R, Bryant B, Wolfe C, Padgett P, DeWalt DA, Weinberger M, Pignone M: The Spoken Knowledge in Low Literacy in Diabetes scale: a diabetes knowledge scale for vulnerable patients. Diabetes Educ 2005;31:215-224

13. Cavanaugh K, Wallston KA, Gebretsadik T, Shintani A, Huizinga MM, Davis D, Gregory RP, Malone R, Pignone M, DeWalt D, Elasy TA, Rothman RL: Addressing literacy and numeracy to improve diabetes care: two randomized controlled trials. Diabetes Care 2009;32:21492155 
14. Rothman RL, DeWalt DA, Malone R, Bryant B, Shintani A, Crigler B, Weinberger M, Pignone M: Influence of patient literacy on the effectiveness of a primary care-based diabetes disease management program. JAMA 2004;292:1711-1716

15. Rothman RL, Malone R, Bryant B, Shintani AK, Crigler B, Dewalt DA Dittus RS, Weinberger M, Pignone MP: A randomized trial of a primary care-based disease management program to improve cardiovascular risk factors and glycated hemoglobin levels in patients with diabetes. Am J Med 2005;118:276-284

16. Wolff $\mathbf{K}$, Cavanaugh $\mathbf{K}$, Malone R, Hawk V, Gregory BP, Davis D Wallston K, Rothman RL: The Diabetes Literacy and Numeracy Education Toolkit (DLNET): materials to facilitate diabetes education and management in patients with low literacy and numeracy skills. Diabetes Educ 2009;35:233-236, 238-241, 244-235

17. National Institute of Diabetes and Digestive and Kidney Diseases (NIDDK), Vanderbilt University: The public private partnership addressing literacy-numeracy to improve diabetes care (PRIDE). In ClinicalTrialsgov Bethesda (MD), National Library of Medicine (NLM), 2011

18. Daniel DM, Norman J, Davis C, Lee H, Hindmarsh MF, McCulloch DK Wagner EH, Sugarman JR: A state-level application of the chronic illness breakthrough series: results from two collaboratives on diabetes in Washington State. Jt Comm J Qual Saf 2004;30:69-79

19. National Diabetes Education Program [article online], 2017. Available from https://nccd.cdc.gov/DDT_DPR/. Accessed 2018 Mar 2

20. Wolff $\mathbf{K}$, Chambers L, Bumol S, White RO, Gregory BP, Davis D, Rothman RL: The PRIDE (Partnership to Improve Diabetes Education) Toolkit: Development and Evaluation of Novel Literacy and Culturally Sensitive Diabetes Education Materials. Diabetes Educ 2016;42:23-33

21. Wallace AS, Seligman HK, Davis TC, Schillinger D, Arnold CL, BryantShilliday B, Freburger JK, DeWalt DA: Literacy-appropriate educational materials and brief counseling improve diabetes self-management. Patient Educ Couns 2009;75:328-333

22. Doak CC, Doak LG, Root JH: Teaching patients with low literacy skills. Philadelphia (PA), J.B. Lippincott Company, 1996

23. Baker DW, DeWalt DA, Schillinger D, Hawk V, Ruo B, BibbinsDomingo $\mathbf{K}$, Weinberger $M$, Macabasco-O'Connell A, Pignone M: "Teach to goal": theory and design principles of an intervention to improve heart failure self-management skills of patients with low health literacy. J Health Commun 2011;16 Suppl 3:73-88

24. Schillinger D, Piette J, Grumbach $\mathbf{K}$, Wang F, Wilson C, Daher C, Leong-Grotz K, Castro C, Bindman AB: Closing the loop: physician communication with diabetic patients who have low health literacy. Arch Intern Med 2003;163:83-90

25. Bowen ME, Cavanaugh KL, Wolff K, Davis D, Gregory RP, Shintani A Eden S, Wallston $\mathbf{K}$, Elasy $\mathbf{T}$, Rothman RL: The diabetes nutrition education study randomized controlled trial: a comparative effectiveness study of approaches to nutrition in diabetes self-management education. Patient Educ Couns 2016;99:1368-1376

26. Baker DW, Williams MV, Parker RM, Gazmararian JA, Nurss J Development of a brief test to measure functional health literacy. Patient Educ Couns 1999;38:33-42

27. White RO, 3rd, Osborn CY, Gebretsadik T, Kripalani S, Rothman RL Development and validation of a Spanish diabetes-specific numeracy measure: DNT-15 Latino. Diabetes Technol Ther 2011;13:893-898

28. Chakkalakal RJ, Venkatraman S, White RO, Kripalani S, Rothman R Wallston K: Validating Health Literacy and Numeracy Measures in Minority Groups. Health Lit Res Pract 2017;1(2):e23-e30

29. Toobert DJ, Hampson SE, Glasgow RE: The summary of diabetes selfcare activities measure: results from 7 studies and a revised scale. Diabetes Care 2000;23:943-950

30. Stetson B, Schlundt D, Rothschild C, Floyd JE, Rogers W, Mokshagundam SP: Development and validation of The Personal Diabetes Questionnaire (PDQ): a measure of diabetes self-care behaviors, perceptions and barriers. Diabetes Res Clin Pract 2011;91:321-332

31. Kripalani S, Risser J, Gatti ME, Jacobson TA: Development and evaluation of the Adherence to Refills and Medications Scale (ARMS) among low-literacy patients with chronic disease. Value Health 2009;12:118-123

32. Biderman A, Noff E, Harris SB, Friedman N, Levy A: Treatment satisfaction of diabetic patients: what are the contributing factors? Fam Pract 2009;26: 102-108

33. Wallston KA, Rothman RL, Cherrington A: Psychometric properties of the Perceived Diabetes Self-Management Scale (PDSMS). J Behav Med 2007;30:395-401

34. Eldridge SM, Ashby D, Feder GS, Rudnicka AR, Ukoumunne OC: Lessons for cluster randomized trials in the twenty-first century: a systematic review of trials in primary care. Clin Trials 2004;1:80-90

35. Harrell FE, Jr: Regression Modeling Strategies. New York, Springer, 2016

36. Rubin DB: Multiple Imputation for Nonresponse in Surveys. New York, Wiley, 1987

37. Gunter KE, Nocon RS, Gao Y, Casalino LP, Chin MH: Medical Home Characteristics and Quality of Diabetes Care in Safety Net Clinics. J Community Health 2017;42:303-311

38. Varkey AB, Manwell LB, Williams ES, Ibrahim SA, Brown RL, Bobula JA, Horner-Ibler BA, Schwartz MD, Konrad TR, Wiltshire JC, Linzer M, Investigators M: Separate and unequal: clinics where minority and nonminority patients receive primary care. Arch Intern Med 2009; 169:243-250

39. Vest BM, Kahn LS, Danzo A, Tumiel-Berhalter L, Schuster RC, Karl R, Taylor R, Glaser K, Danakas A, Fox CH: Diabetes self-management in a low-income population: impacts of social support and relationships with the health care system. Chronic Illn 2013;9:145-155

Publisher's Note Springer Nature remains neutral with regard to jurisdictional claims in published maps and institutional affiliations. 